\title{
Macedonia from Fragments to Pixels: A Permanent Exhibition of Interactive Systems at the Archaeological Museum of Thessaloniki
}

\author{
Dimitris Grammenos ${ }^{1}$, Xenophon Zabulis ${ }^{1}$, Damien Michel ${ }^{1}$, Pashalis Padeleris ${ }^{1}$, \\ Thomas Sarmis ${ }^{1}$, Giannis Georgalis ${ }^{1}$, Panagiotis Koutlemanis ${ }^{1}$, \\ Konstantinos Tzevanidis ${ }^{1}$, Antonis A. Argyros ${ }^{1,2}$, Michalis Sifakis ${ }^{1}$, \\ Polyxeni Adam-Veleni ${ }^{3}$, and Constantine Stephanidis ${ }^{1,2}$ \\ ${ }^{1}$ Institute of Computer Science, Foundation for Research and Technology Hellas \\ ${ }^{2}$ Computer Science Department, University of Crete, Greece \\ ${ }^{3}$ Archaeological Museum of Thessaloniki, Greece \\ \{gramenos, zabulis, michel, padeler, sarmis, jgeorgal, koutle, \\ ktzevani, argyros, misi\}@ics.forth.gr, pveleni@culture.gr, \\ cs@ics.forth.gr
}

\begin{abstract}
The theme of this paper is an exhibition of prototypical interactive systems with subjects drawn from ancient Macedonia, named "Macedonia from fragments to pixels". Since 2010, the exhibition is hosted by the Archaeological Museum of Thessaloniki and is open daily to the general public. Up to now, more than 165.000 people have visited it. The exhibition comprises 7 interactive systems which are based on some research outcomes of the Ambient Intelligence Programme of the Institute of Computer Science, Foundation for Research and Technology - Hellas. The digital content of these systems includes objects from the Museum's permanent collection and from Macedonia.
\end{abstract}

Keywords: Interactive exhibits, edutainment, museum, interaction design.

\section{Introduction}

In 2010, the Institute of Computer Science of the Foundation for Research and Technology-Hellas (ICS-FORTH) and the Archaeological Museum of Thessaloniki (AMTh) have collaborated towards the creation of a special exhibition of prototypical interactive systems with subjects drawn from ancient Macedonia, named "Macedonia

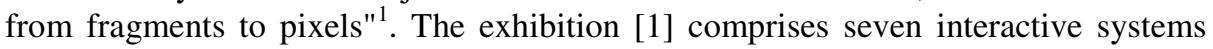
which are based on the research outcomes of ICS-FORTH's Ambient Intelligence Programme. The digital content of these systems includes objects from the Museum's permanent collection and from Macedonia in general.

The resulting exhibition is very different from a typical archaeological exhibition, as the public can have a new relationship with exceptional artifacts of the past through the use of new technologies, enjoying an interactive experience that combines

\footnotetext{
${ }^{1}$ http : / / www . makedonopixels.org
} 
learning with entertainment. In this way, visitors have the opportunity to approach classical antiquity in a novel manner: by exploring digital reproductions of ancient masterpieces. Rare and fragile artifacts are now at the public's fingertips with the use of modern and user friendly technology. All systems are multilingual and support interaction by one or multiple visitors. The exhibition is hosted by the AMTh at its premises and is open daily to the general public.

\section{Creating the Exhibition}

In 2009, in the context of the "Ambient Intelligence and Smart Environments" Programme of ICS-FORTH [2], a multidisciplinary team was set up aiming to explore and experiment with the creation of novel interactive edutainment exhibits for museums and assess their utility, usability and potential impact. The preliminary results of this activity were presented, among others, to the Director of the Archeological Museum of Thessaloniki, who expressed her vivid interest towards realizing a permanent installation of such systems at AMTh. Eventually, a bilateral project was setup between the two organizations, comprising two multi-disciplinary teams. ICS-FORTH's team counted 16 members, including interaction designers, programmers, computer scientists, electronic engineers, and graphic artists, and was mainly responsible for designing, developing, installing and supporting the interactive exhibits. The Museum's team included four archaeologists, two architects / museologists, and several technicians whose main tasks were to provide the required digital content, as well as to design and construct the exhibition spaces and contribute to the design of the interactive exhibits so that they would best serve the requirements and functional role of the Museum. In brief, the overall process followed can be summarized as follows (Fig. 1).

During the initial brainstorming phase of the project, the number, nature, location and basic theme of the interactive systems that would be installed were agreed. In this context, it was decided to install five exhibits in a dedicated, specially designed hall of the Museum, and to two more in the Museum's permanent exhibition on ancient Macedonia.

Subsequently, the two teams started working collaboratively and in parallel towards designing the installation spaces, shaping the interaction design and technical requirements of the exhibits and collecting and formulating appropriate multimedia content. In this context, a highly user-centred, iterative process was followed where the outcomes of the work of one team frequently resulted in changes to the work of the other. Different types and levels of prototypes, ranging from simple sketches to functional digital applications were employed so that all project members could have a clear understanding of the systems that were being created, how they would interact with their users, what kind of multimedia content would provide and how.

When a system under development reached a fairly stable level, it was installed at a dedicated space simulating a museum room in the premises of ICS-FORTH and was further tested and evaluated by experts as well as by a highly diverse group of potential end-users.

When all systems were ready, they were installed at the Museum, and were further tested and evaluated for a couple of weeks with archaeologists, museum guards and 
visitors, a process that led to further refinements of both their interface and digital content. For all systems, a working copy of the artifact was also assembled to be able to replicate and study early prototype failures.

On-going technical support is mainly performed remotely through screen sharing applications, teleconferencing, e-mails and phone calls. To date, occasional site visits by FORTH technicians to the Museum were due to exceptional hardware failures.

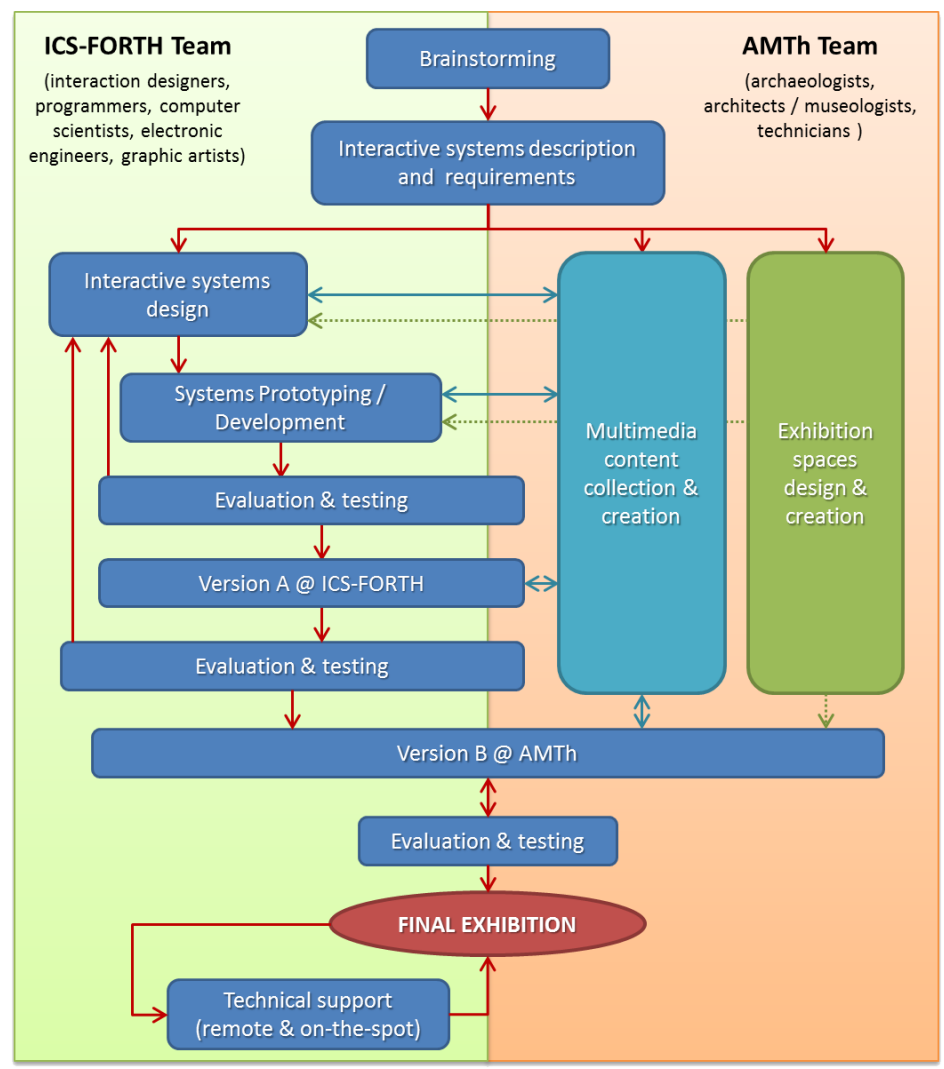

Fig. 1. Process followed for creating the exhibition

\section{The Exhibition}

The exhibition comprises seven systems, five of which are located at a specially designed hall of the Museum, while the remaining two have been incorporated into the Museum's permanent exhibition on ancient Macedonia. The applications running on all systems were developed using Flash ActionScript, while the low-level services that drive the hardware sensors were implemented in .NET (C\#), C++ and CUDA. An in-house, custom-made middleware layer based on CORBA was used [3] by all the exhibits to allow the interactive applications and various software services to communicate, despite their heterogeneity. 


\section{i. Panoptes, the All-Seeing: Gold Macedonian Wreaths}

Panoptes [4] (Fig. 2) is a digital exhibition-catalogue system which allows visitors to browse its content and dwell on details of images, read accompanying texts and follow threads of information. Panoptes presents the AMTh gold Macedonian wreaths collection, the most extensive such collection in the world. These wreaths are among antiquity's most exquisite examples of ancient jewelry, and show a lot about the people who wore them. A children's windmill is located between two touch screens (one larger, one smaller). Blowing on the windmill, the visitor can browse the largest collection of gold wreaths in the world and discover information about each one of them. The user can zoom-in on any detail of the presented images, as well as, choose regions of interest, marked on the image, to show pertinent multimedia information.

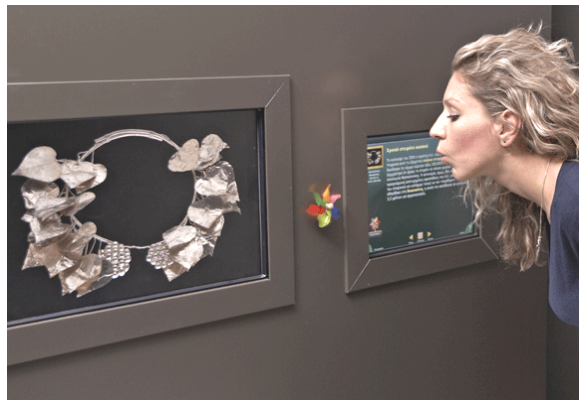

Fig. 2. Panoptes, the all-seeing

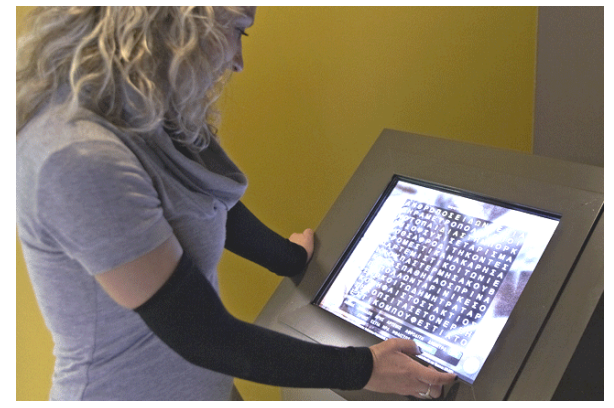

Fig. 3. Cryptolexon, mystery word puzzle

\section{ii. Cryptolexon, Mystery Word Puzzle: Hidden Gods and Heroes}

Cryptolexon (Fig. 3), the hidden crossword, is a game loved by all ages, which combines entertainment with knowledge. The names of ancient gods and heroes are hidden within a matrix of letters for the visitors to discover. On the easiest level, players can find the twelve gods of Mount Olympus; as the degree of difficulty increases, heroes and lesser known local gods are also included. The system uses a touch screen. Visitors can discover the hidden words by dragging a finger from the start to the end of each word or, alternatively, by touching each word's first and last letter. Once a word has been found, information is presented about it.

\section{iii. Polyapton: A Symposium from the Macedonian Tomb of Agios Athanasios}

Polyapton [4; 5] (Fig. 4) is a very large interactive screen that can be used by several visitors who wish to explore multifaceted information on a subject at the same time. Polyapton presents one of the best-preserved ancient Greek paintings. It is a wall painting depicting a symposium, from the Macedonian tomb of Agios Athanasios near Thessaloniki. The tomb is not open to visitors, who have here a rare opportunity to enjoy the painting in its full glory. The system's special multi-touch capabilities are achieved through computer vision techniques that are able to recognize the touch of many fingers or hands, but also of specific objects, at the same time. Visitors can 'scroll' across the painting and focus on points of interest with multimedia information by touching them, zoom in on details with the use of a paper magnifying lens, while an infrared torch displays a modern rendition of the painting. 


\section{iv. Macrographia: A Room with View... on Aigai}

Macrographia [6;7] (Fig. 5) is a system that presents very large images, which visitors can explore by walking around in a room. The images are projected on a screen and are analyzed part-by-part depending on the location of each visitor in the room. Macrographia presents the "Wall-painting of the Royal Hunt" from the tomb of Philip II at Vergina, ancient Aigai, a large work of art, presented almost in real size. This is the largest ancient Greek painting that has been found to date, its length exceeding 5.5 meters. It is dated in $336 \mathrm{BC}$, the year when Philip was murdered, and decorates the front of the tomb of the great king. The system occupies an entire room, with one wall being the back projection screen. As visitors enter the room, a computer vision subsystem is able to reconstruct them in $3 \mathrm{D}$, understand aspects of their posture and track them in real time. The images projected in front of each visitor change according to her/his location in the room. The painting is divided into five sections, which correspond to the prey of the hunters. When someone stands in front of a section, depending on the distance from the screen, the image she/he views and the caption underneath change. There are four levels of information: the present state of the painting, an artist's sketch, an artist's modern rendition, and notable details. Visitors can select the language of the accompanying text by entering the room from the left (for Greek) or right side (for English).

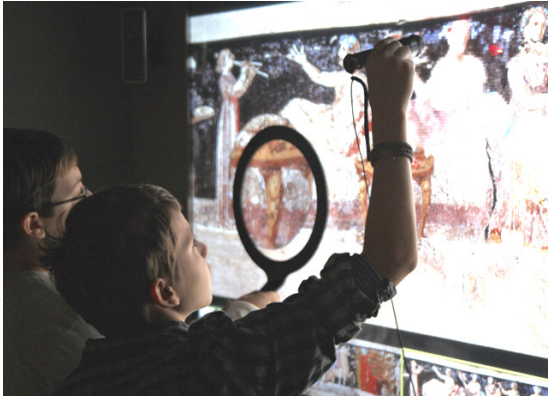

Fig. 4. Polyapton, a custom multitouch screen with additional capabilities

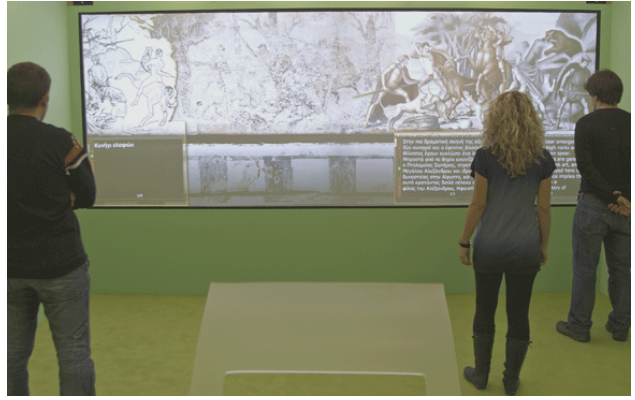

Fig. 5. Macrographia: A room with view... on Aigai

\section{v. Multimodal Diverse Travel: Travel in Space and Time with a Piece of Paper}

Multimodal Diverse travel [8; 9] (Fig. 6) enables more than one visitor at the same time to interactively explore information about various areas and points of a map of Macedonia. The system comprises a table, whose surface is covered by a printed map on which the location of various cities and other notable sites is projected. White paper tablets with a colored frame are at the visitors' disposal. On each tablet a magnifying glass is displayed. When the magnifying glass is placed over a city, related images, videos and texts appear on the tablet. For every city there are multiple information "pages", which can be viewed by touching virtual buttons at the bottom of the tablet. The color of the frame of each tablet designates the language in which information is presented. 


\section{vi. One Day in a Farmstead: Discover an Ancient Farmstead}

This system [8; 9] (Fig. 7) allows visitors to retrieve information about an ancient farmstead of the 4th century BC that has been excavated at Asprovalta near Thessaloniki. This is achieved by enriching a scale model with multimedia information in one of the main exhibition areas of the Archaeological Museum of Thessaloniki. The system behaves similarly to the Multimodal Diverse travel, with the following differences (a) when the paper tablet is located over a point of interest, a short animation is presented that starts from a view of the piece of the model located underneath and is gradually transformed into the respective area of the actual excavation site, so that visitors can visually correlate them; (b) due to the glass surface, no information is projected outside the tracked papers.

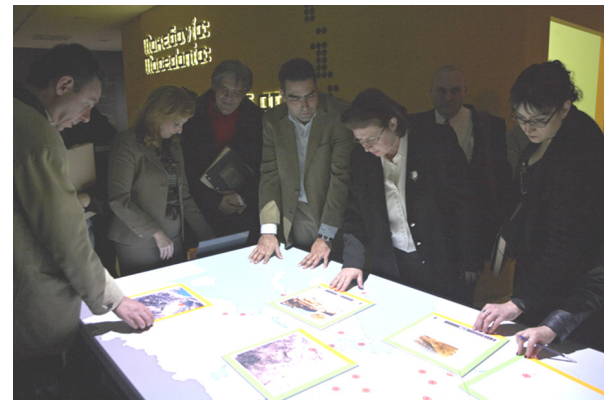

Fig. 6. Multimodal Diverse travel

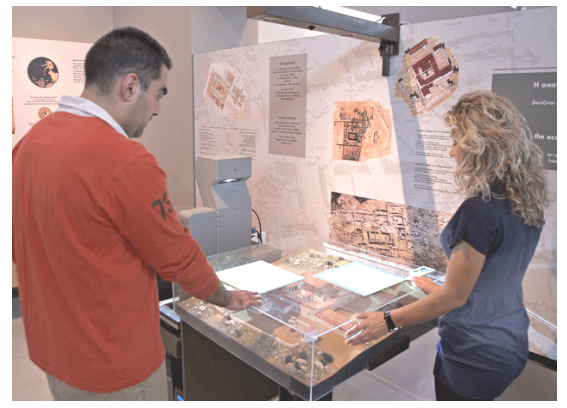

Fig. 7. One day in a farmstead

\section{vii. Peridexion, the Dexterous: The Myth of Melager and the Calydonian Boar}

Peridexion (Fig. 8) is a system that offers museum visitors the possibility of exploring an object and/or a subject in depth. Peridexion presents a masterpiece of 6th c. BC Athenian black-figured pottery, the Crater of Lydos, and three exceptional examples of Roman sculpture from the AMTh collection, all of which draw inspiration from the legend of the hunt of a monstrous boar in Calydonia, Aetolia. This myth is not widely known today, as most relevant ancient texts have not survived, but was at times very popular in antiquity, and a source of inspiration for artists for a very long time.

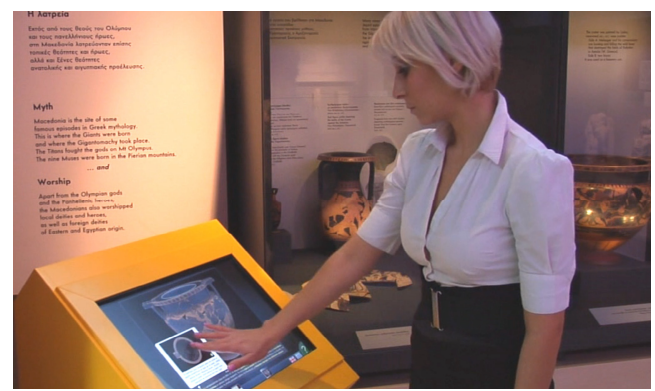

Fig. 8. Peridexion, the dexterous 
The objects included in this presentation span eight centuries. The system has a touch screen that presents a view of an object at a time. Visitors can select the object or the view they wish to see and then discover points of interest and relative multimedia information, or zoom in on any detail at will. The system is located at the exhibition "At the kingdom of Macedonia", unit: "Myth and worship", next to the real artifact.

\section{Conclusions}

"Macedonia from fragments to pixels" exhibition combines images, sounds, texts with user interaction in novel ways aiming to create a pleasant dynamic environment supporting user exploration and experimentation. The key design elements of the overall approach are usability, aesthetics, entertainment coupled with scientifically valid knowledge and the element of surprise. Simple, ordinary objects, such as a toy windmill, a magnifying glass made of plastic, or even a plain piece of cupboard, magically become "alive" through the aid of ambient Intelligence Technologies and are converted to fun tools for knowledge discovery. In essence, the presented systems achieve to expand the static museum environment in time and space. Surfaces with a limited and fixed size, as for example a printed map, become able to encompass and present an infinite number of information pieces. At the same time, visitors can have a glimpse of the past, the present, or even the future by interacting with the systems.

As a result, the museum space becomes more friendly and interesting, a fact that is also proved through a raise of AMTh's visitation since the day that the exhibition opened its gates to the public. Additionally, the exhibition received considerable publicity, initially through the mass media and the Internet, and subsequently through word-of-mouth "advertising". The public's response was beyond any expectation, while schools need to enroll in a waiting list in order to get a chance of visiting the exhibition. Additionally, the comments made by museum visitors range from positive to enthusiastic, while results stemming from more formal "in situ" evaluations (e.g, [7]) reinforce these findings. Up to now, it is estimated that more than 165.000 people have seen the exhibition, out of which 42.000 were children 6 to 16 years old, in the context of organized school visits.

From a scientific point of view, the project generated several innovative research results which were documented in academic publications (e.g., $[1 ; 2 ; 3 ; 4 ; 5 ; 6 ; 7 ; 8$; 9], a number of which stemmed from the collaboration between domains, such as computer vision and human-computer interaction (e.g., Polyapton [4; 5], Macrographia [6 ;7], Multimodal Diverse travel and One day in a farmstead [8; 9]). Additionally, the project provided an invaluable platform for studying interactive exhibits in situ, in an environment which is visited daily by several hundreds of visitors of diverse ages and nationalities.

Since all exhibits use a common middleware layer, their integration and communication at a semantic is facilitated, aiming towards a seamless interaction flow, that offers visitors a unified experience. Ongoing work includes the investigation of the application of the project's results in more types of museums. Future work, concerns identification of users, to support the adaptation of the interactive experience and 
presented content according to interaction history, preferences, and individual needs. After leaving the museum visitors will be able to access and review information about their visit through the Internet, as well as suggestions and further material based on their interaction history and perceived interests.

Acknowledgments. This work has been supported by the FORTH-ICS RTD Programme "Ambient Intelligence and Smart Environments".

\section{References}

1. Zabulis, X., Grammenos, D., Argyros, A., Sifakis, M., Stephanidis, C.: Macedonia: From Fragments to Pixels. ERCIM News, Special Theme: ICT for Cultural Heritage 86, 25-26 (2011)

2. Grammenos, D., Zabulis, X.C., Argyros, A.A., Stephanidis, C.: FORTH-ICS internal RTD programme 'ambient intelligence and smart environments. In: 3rd European Conference on Ambient Intelligence, Salzburg, Austria (2009)

3. Georgalis, Y., Grammenos, D., Stephanidis, C.: Middleware for Ambient Intelligence Environments: Reviewing Requirements and Communication Technologies. In: Stephanidis, C. (ed.) UAHCI 2009, Part II. LNCS, vol. 5615, pp. 168-177. Springer, Heidelberg (2009)

4. Grammenos, D., Zabulis, X., Michel, D., Sarmis, T., Georgalis, G., Tzevanidis, K., Argyros, A., Stephanidis, C.: Design and Development of Four Prototype Interactive Edutainment Exhibits for Museums. In: Stephanidis, C. (ed.) HCII 2011 and UAHCI 2011, Part III. LNCS, vol. 6767, pp. 173-182. Springer, Heidelberg (2011)

5. Michel, D., Argyros, A.A., Grammenos, D., Zabulis, X.C., Sarmis, T.: Building a multitouch display based on computer vision techniques. In: Proceedings of the IAPR Conference on Machine Vision and Applications (MVA 2009), Hiyoshi Campus, Keio University, Japan, pp. 74-77 (2009)

6. Zabulis, X., Grammenos, D., Sarmis, T., Tzevanidis, K., Argyros, A.A.: Exploration of large-scale museum artifacts through non-instrumented, location-based, multi-user interaction. In: Proc. of VAST 2010 (2010)

7. Zabulis, X., Grammenos, D., Sarmis, T., Tzevanidis, K., Padeleris, P., Koutlemanis, P., Argyros, A.A.: Multicamera human detection and tracking supporting natural interaction with large scale displays. Machine Vision Applications Journal (February 2012) (published online)

8. Grammenos, D., Michel, D., Zabulis, X., Argyros, A.A.: PaperView: augmenting physical surfaces with location-aware information. In: Procs of TEI 2011, pp. 57-60 (2011)

9. Grammenos, D., Zabulis, X., Michel, D., Argyros, A.A.: Augmented Reality Interactive Exhibits in Cartographic Heritage: An implemented case-study open to the general public. In: The Proceedings of the 6th International Workshop on Digital Approaches in Cartographic Heritage, The Hague, Netherlands, e-Perimetron, April 7-8, vol. 6(2), pp. 57-67 (2011) 